\title{
LEADERSHIP ISSUES \\ IN TIMES OF GLOBAL PANDEMIC
}

\author{
Diana CHIȘ-MANOLACHE \\ dianamanolache88@yahoo.com
}

“CAROL I” NATIONAL DEFENCE UNIVERSITY, BUCHAREST, ROMANIA

\begin{abstract}
At present, humanity is facing a multitude of problems caused by the SARS-CoV-2 pandemic, that requires a continuous adaptation to all organizational levels. Regarding the management of organizations, it is clear that this one has to be adapted to the current situation and to the needs of members of the organizations which have also undergone profound changes. In this regard, leaders at all levels of the organization must act flexibly, be attentive to the needs of teams and reshape their leadership style to respond to the uncertain realities that govern the world order.
\end{abstract}

\section{KEYWORDS:}

Adaptation, leadership, organizations, pandemic, transformation

\section{Introduction}

All over the world, in the current period, the COVID-19 pandemic creates an extremely dark picture, affecting all sectors of human activity, forcing humans to bring radical changes, in several levels.

We all go through an unprecedented period, a period to which we are obliged to adapt, regardless of the organization in which we carry out our activity and the place we occupy in it. Considering the effects of the COVID-19 pandemic worldwide, the entire world is in a continuous transformation, the insecurity and the unpredictability governing the organizations and the lives of the people.

In this context, the multiple organizational sufferings of mankind are closely connected with the problems of leaders who are actually struggling to adapt to new realities, constantly changing elements, with the evolution of business reality and more.

At the same time, all changes are required to happen in a fast rhythm, and leaders are required to inoculate a multitude of transformations within organizations, to adopt new leadership strategies, and to be able to shape their own ideas in order to adapt to the new situations.

Considering all these aspects, it was strictly imposed the need that leaders adopt an authentic leadership, adapted to the current reality, and to the needs of all members of the organizations. The whole society needs strong leaders to guide change and to identify new elements of support in this field. 


\section{Research methodology}

The approach to leadership issues in the context of the global pandemic is the result of an empirical documentary analysis conducted by studying and analyzing existing documents in the current period, regarding the implications of the COVID-19 pandemic on the leadership of organizations.

Considering the fact that the observation is the first method of data collection used, the paper is mainly based on explanatory research, research that has highlighted the factors that determine the need to impose changes in leadership in sensitive situations, such as the current health crisis.

On the one hand, the approach of some examples from the leadership experience of developed countries governments and on the other hand, the examples resulting from the multinational companies management, are the result of an empirical documentary analysis and the conclusions and proposals developed could be the basis for a new, much more complex and extensive documentary study. The empirical research realized will open new, current research directions, being strongly anchored in the reality of today. Also, considering the complexity of the current health crisis, I consider it is essential to implement new elements in terms of organizational leadership that must be flexible and adapted to current realities.

\section{Leadership in crisis situations}

As much as humanity faces this global pandemic, the actions of leaders at all hierarchical levels acquire a special importance, the strategies and means used by them being essential in managing all aspects of this crisis. Also, a series of organizational questions arise in the collective mind when it comes to the assessment of the way to manage the crisis.

When deciding how to manage the crisis, do leaders use a whole-system perspective? How clear, coherent, consistent, and truthful are the data used in the decision-making process? Which are the most important elements taken into consideration by leaders in pandemic management?

Are all team members involved in solving problems?

The perception of the way leaders lead, highlighting the system, the organization, but also its members, can be an important tool for evaluation. Also, considering all these, it is shown the impact over time of the use of strategies that optimize the whole, value the data, and support and encourage cooperation.

The actual period that we are confronted with is very rarely in history, being marked by moments when we can evaluate the effectiveness of leadership in real time. In other words, the speed with the virus circulates is directly proportional to the impact of each leader's actions. As this pandemic reveals its ramifications affecting all of humanity, there are highlighted the ability of leaders to lead, to communicate, to make decisions, to be flexible and creative.

The challenges are huge, and now, more than ever, people in key positions need to act, to take a rational command and to make the right decisions, no matter what dangers they may face. This is the time for true leaders to emerge. Of course, if they are let to.

In these extremely sensitive moments, leaders are challenged to manage a lot of unknown, unique and tense situations. While leaders provide vision, orientation, direction, guidance, they realize that they must follow an extremely blurred and shady path. All these situations require the existence of leaders capable of leading with great tact, with humanity and to do some important things that we will list in the following chapter. 


\section{Some proposals for improving leadership in organizations}

\subsection{Empowering subordinates and delegating responsibilities}

In times of crisis, such as the current one, marked by the emergence of the pandemic, a big mistake that leaders at any hierarchical level could make in managing all activities is to try to control absolutely everything and to super centralize the decision-making process.

In this sense, leaders at the top level, whether they are leaders in government, in the military structures or companies, must empower those who lead the front lines. This fact involves the inoculating of a clear set of values and guiding principles to people in key positions and encouraging them to make decisions that conform to those principles. The delegating of responsibilities and building people's confidence in times of crisis are essential.

Considering all dangers created by this pandemic, a key guiding principle is that the human health and the well-being of people are the most important aspects that leaders should take care and people should never be put at unnecessary risk.

\subsection{In the hierarchy of priorities, people must be in the first position}

The most important resource of an organization is the human one, and during the pandemic it must be supported and valued. Preserving and maintaining the safety and the well-being of members of organizations must be included in the list of organizational priorities for each leader.

Employees hardly focus or just cannot focus on their professional responsibilities if their well-being or the well-being of their family members are at risk. Therefore, the key issue that companies need to address is whether their employees feel safe and whether they are available to perform critical functions. There is very important for organizations to be able to monitor the situation, to provide a secure job to employees and to provide the necessary support to them.

A relevant example of a company that has supported its employees throughout the pandemic is Las Vegas Sands, which has offered all the corresponding financial rights to all 10,000 employees (Sundheim, 2020), even though the properties have been closed. The Dallas Mavericks also kept all its seasonal employees (Sundheim, 2020), although it did not work for a long time.

Also, VillageMD clinic, which has about 2,700 employees and partners around the United States, registered a huge shortage of patients, but managed to keep its employees, managing to perform remote consultations, performing that telemedicine. Flexibility and ability to adapt to the new conditions were demanded from everyone and fortunately, they were successfully obtained.

\subsection{The supporting of employees and their treating with empathy}

The pandemic has a different impact from previous crises. People's health, work, personal and social life are threatened, they become anxious, but they do their best to move on. Some of them work in hospitals, in the first line of fighting the disease, others continue their professional activity working from home, others are left without jobs (the worst case scenario). Children try to learn online and they miss their friends. Elderly loved ones are in great danger, fact that provoke a lot of fear.

At the same time, financial issues, such as rents, mortgages are creating unrest among people. That's why, leaders must support employees and empathize with them. For leaders, all of this requires slowing down the pace, flexibility and the employees supporting in confronting these new challenges. It also means a deeper connection opportunity.

For example, for Neil Sprackling, the president of U.S. Life \& Health, connecting on a personal level was a priority. 
"The beginning and the end of each interaction between employees and customers, I try to achieve by discussing personal elements", he said (Sundheim, 2020). These aspects seem to be insignificant, but they contribute to the consolidation of close relationships and to the maintenance of the mental health of the employees.

\subsection{Take swift and decisive actions}

During the crisis caused by the new coronavirus, it was observed that, in general, in countries where the actions taken by government leaders were carried out early and decisively, they led to a reduction in the spread of the number of cases of disease.

For example, in New Zealand the pandemic was very well managed by the Prime Minister, Jacinda Ardern, who set an example to most Western politicians in leading this crisis (Wilson, 2020). This fact is explained by taking fast decisions to close public spaces, and this was a successful measure to fight against the pandemic.

At a time when New Zealand had only 52 confirmed cases of COVID-19, it was set a level two alert, with some travel restricted and people urged to limit contact. Four days later, when 205 cases were registered, the alert system was raised to level four, triggering a real blockage at the national level (people left their homes only to solve the problems of strict necessity, most were closed public institutions, people continued their professional activities at home, etc.).

All the decisions taken by Jacinda Ardern in those moments of crisis were characterized by firmness, speed and courage.

The effective management of this crisis in Taiwan and the rapid reporting of the outbreak can also be seen as an example of how democratic countries can deal with epidemics. The Taiwanese government, led by Tsai Ing-wen, Taiwan's first female president, has taken strict measures in advance, such as: travel bans, drastic sanctions for those who violated home quarantine rules, but also extensive testing.

\subsection{Firm actions, without excessive planning}

Given the specificity of this crisis, leaders at all hierarchical levels must prioritize all efforts on the implementation of all plans in a very short time, streamlining the decision-making process. At the same time, the stabilization in terms of the efficient functioning of the organization in a short time horizon is one of the priorities of the leaders.

The measures taken in times of crisis such as the coronavirus outbreak have been exceptional, but organizational leaders must also focus on the immediate steps needed to stabilize the situation and mitigate damage (restoring human security, resuming activities, etc.). Leaders need to prepare their organizations for overcoming the crisis, but also for the post-crisis period. As Professor Mauro F. Guillén states, "plans are useless during a crisis, but planning is essential" (Quartz Staff, 2020).

\subsection{Developing an effective communication strategy in times of crisis}

It is well known that, during a crisis, along with other aspects, communication occupies an essential place for people, being the one that can restore morale, confidence and balance. Although most leaders have well-crafted communication strategies and make important speeches, the messages conveyed are not always clear.

An example of an extremely clear and empathetic speech is that of the Prime Minister of New Zealand, Jacinda Ardern. When she publicly announced that she had reached alert level 4 and the need to block social contacts, the speech was clear, honest and full of empathy. She acknowledged all the sacrifices corresponding to these measures and inspired people to move forward together. 
She also guided and directed the New Zealanders in that huge fog of uncertainty, strengthening their belief that the Government would support them throughout the crisis.

At the same time, Ardern thanked the New Zealanders for everything they were going to do, confirming that it is not easy at all. At the end of the speech, she asked the people to be strong, supportive and united against Covid-19 (Kerrissey \& Edmondson, 2020).

Moreover, in times of crisis, the appearance of fake news and reports on social media creates great confusion and deepens the feeling of uncertainty among the population. In this sense, leaders are required to provide coherent and timely messages, and companies need to develop a robust communication strategy that clearly sets out the communication process and protocols with a wide range of stakeholders (eg customers, contract partners, regulators, employees, third parties, government authorities, the press, medical staff), including any legal and jurisdictional considerations.

\subsection{Achieving the things that really are necessary, at the risk of becoming unpopular}

Given all the above points, in a situation of acute crisis, both leadership and management are vital for organizations. We certainly need strong leaders who face reality, pursue performance, take responsibility, and "do the right thing" (Bennis, 2003, p. 23). In times of crisis, more than ever, wellmodeled leaders and managers are needed. All organizations need leaders who can manage activities with a high degree of novelty, who can guide and influence people to achieve organizational goals. They must be able to communicate the bad news and confess uncomfortable truths when necessary. But more than that, they should not be afraid to make decisions that may be unpopular, regardless of whether their position is at stake.

\section{Conclusions}

In times of crisis such as the present one, both governments and public institutions and companies are forced to test their ability to react and adapt, but at the same time they are challenged to test the leadership skills of leaders, that are really essential. Moreover, the context created by the global pandemic offers organizations the opportunity to test the most important values of employees such as: loyalty, involvement, commitment and, above all, trust. It is about the trust of the team members in the leaders, as well as that of the leaders in the subordinates, but also the trust between people situated on the identical/similar levels of the organization.

Lately, leadership has been in the attention of many theorists, all translating this concept into different terms and values, highlighting a distinct hierarchy of priorities before the pandemic broke out. Broadly speaking, the leadership has evolved a lot lately, but in strict connection with the realities of balanced societies, with an emphasis on influencing, supporting and directing people to evolve and perform on many levels. Instead, in the new context outlined by the COVID-19 pandemic, the essential elements of leadership have acquired new valences, with leaders being forced to adapt to the new reality and succeed in supporting subordinates to do the same. Moreover, leaders have the obligation to manage the general uncertainty and confusion in order to succeed in balancing situations, but also the mental balancing of individuals.

Given the proposals listed above, an essential leadership skill that can make the difference is to quickly identify the transformations that are required, to manage them as rigorously as possible, as quickly as possible, so that the impact of negative events on the organization and on most employees to be minimal.

Moreover, the ability of leaders to communicate objectively, transparently, clearly and empathically, but also to 
maintain a high level of positivism that motivates the team and inspires courage, is of substantial importance. Today, both leadership and adaptability are essential for both leaders and teams.

During a crisis like the one humanity is going through now, it is extremely important for leaders to show flexibility in thinking in order to be able to explore a wide range of approaches and opportunities, some even unconventional. Not infrequently, the history has shown that in certain unfavorable contexts, beyond the obvious aspects, real possibilities for evolution can be identified, and often a crisis is a good time to reinvent. These elements require combined effort, adaptability, perseverance, flexibility in thinking and creativity.

\section{REFERENCES}

Bennis, W. (2003). On becoming a leader: The leadership classic. Revised and updated Edition, Cambridge, MA: Perseus Publication.

Kerrissey, M. J., \& Edmondson, A. C. (2020). What good leadership looks like during this pandemic. Harvard Business Review, available at: https://hbr.org/2020/04/what-goodleadership-looks-like-during-this-pandemic, accessed on 11 May 2020.

Quartz Staff. (2020). Mauro Guillen on how the pandemic is accelerating history. The New Normal, available at: https://qz.com/1869405/mauro-guillen-on-the-futureimpacted-by-coronavirus, accessed on 10 June 2020.

Sundheim, D. (2020). When crisis strikes, lead with humanity. Harvard Business Review, available at: https://hbr.org/2020/04/the-best-leaders-meet-a-crisis-with-humanity, accessed on 01 May 2020.

Wilson, S. (2020). Three reasons why Jacinda Arderns coronavirus response has been a masterclass in crisis leadership. The Conversation, available at: $\underline{\mathrm{https}: / / \text { theconversation.com/ }}$ three-reasons-why-jacinda-arderns-coronavirus-response-has-been-a-masterclass-in-crisisleadership-135541, accessed on 10 May 2020. 